\title{
CFSv2-based sub-seasonal precipitation and temperature forecast skill over the contiguous United States
}

\author{
Di Tian ${ }^{1,2}$, Eric F. Wood ${ }^{1}$, and Xing Yuan ${ }^{3}$ \\ ${ }^{1}$ Department of Civil and Environmental Engineering, Princeton University, Princeton, New Jersey 08544, USA \\ ${ }^{2}$ Department of Crop, Soil, and Environmental Sciences, Auburn University, Auburn, Alabama 36849, USA \\ ${ }^{3}$ CAS Key Laboratory of Regional Climate-Environment for Temperate East Asia (RCE-TEA), \\ Institute of Atmospheric Physics, Chinese Academy of Sciences, Beijing 100029, China \\ Correspondence to: Di Tian (tiandi@auburn.edu)
}

Received: 22 July 2016 - Revised: 4 August 2016 - Accepted: 19 January 2017 - Published: 9 March 2017

\begin{abstract}
This paper explored the potential of a global climate model for sub-seasonal forecasting of precipitation and $2 \mathrm{~m}$ air temperature. The categorical forecast skill of 10 precipitation and temperature indices was investigated using the 28-year sub-seasonal hindcasts from the Climate Forecast System version 2 (CFSv2) over the contiguous United States (CONUS). The forecast skill for mean precipitation and temperature as well as for the frequency and duration of extremes was highly dependent on the forecasting indices, regions, seasons, and leads. Forecasts for 7- and 14-day temperature indices showed skill even at weeks 3 and 4 , and generally were more skillful than precipitation indices. Overall, temperature indices showed higher skill than precipitation indices over the entire CONUS region at sub-seasonal scale. While the forecast skill related to mean precipitations was low in summer over the CONUS, the number of rainy days, number of consecutive rainy days, and number of consecutive dry days showed considerably high skill for the western coastal region. The presence of active Madden-Julian Oscillation (MJO) events improved CFSv2 weekly mean precipitation forecast skill over most parts of the CONUS, but it did not necessarily improve the weekly mean temperature forecasts. The 30-day forecasts of precipitation and temperature indices calculated from the downscaled monthly CFSv2 forecasts were less skillful than those calculated directly from CFSv2 daily forecasts, suggesting the usefulness of CFSv2 for sub-seasonal hydrological forecasting.
\end{abstract}

\section{Introduction}

Sub-seasonal (or intra-seasonal) timescale forecasts are typically between medium-range weather forecasts $(1$ or 2 weeks) and seasonal climate predictions (1 to 12 months). The medium-range weather forecast is strongly influenced by atmospheric initial conditions (Vitart et al., 2008), while the seasonal climate forecast depends on slowly evolving components of the climate system (e.g., sea surface temperature and soil moisture) (Troccoli, 2010). However, since the subseasonal timescale is usually too long to be favored by the atmospheric initial conditions (Vitart, 2004) and too short to be strongly influenced by the variability of the ocean, making skillful sub-seasonal forecasts is particularly difficult and thus far has less progress than the medium-range weather forecasts and seasonal climate forecasts.

Since many extreme events (e.g., flash drought, heat wave, and cold wave) and their corresponding management decisions fall into sub-seasonal timescales, accurate sub-seasonal forecast information will be central to the development of climate services and therefore has great socioeconomic value (Vitart et al., 2012). In fact, sub-seasonal forecast information can be useful for developing strategies for proactive natural disaster mitigation (Brunet et al., 2010; Vitart et al., 2012). Previous studies have evaluated the potential of sub-seasonal to seasonal forecasts for heat wave forecasting (e.g., Hudson et al., 2011a; White et al., 2014), hydrological forecasting (e.g., Orth and Seneviratne, 2013; Yuan et al., 2014), water resources management (e.g., Sankarasubramanian et al., 2009), hydropower production management (e.g., Garcia-Morales and Dubus, 2007), and crop yield predic- 
tion (e.g., Hansen et al., 2006; Zinyengere et al., 2011). Due to the improvement of numerical models, prediction techniques, and computing resources, there is an increasing focus on sub-seasonal forecasts (e.g., Toth et al., 2007; Vitart et al., 2008; Brunet et al., 2010; Hudson et al., 2011b, 2013; Robertson et al., 2014).

Precipitation and $2 \mathrm{~m}$ temperature (hereafter temperature) are considered as two of the most important climate variables that significantly influence irrigation scheduling, urban water supply, cooling water related to thermal power generation, hydropower operations, etc. Many important subseasonal events, including heat waves, cold waves, dry spells, and wet spells, are directly derived from the frequency, duration, and intensity of rainfall or hot (cold) temperature. While several studies have been conducted to forecast the duration of high-temperature days (i.e., heat waves) (e.g., Hudson et al., 2011a; Luo and Zhang, 2012; White et al., 2014), there has been, thus far, no complete investigation of sub-seasonal forecasting capabilities for the other temperature and precipitation indices that are directly associated with important events and decision-making. In this study, we aim to evaluate the skill of sub-seasonal forecasting for those precipitation and temperature indices, including mean, frequency, duration, and intensity of precipitation and temperature at subseasonal timescale, such as the number of dry/wet days and the number of cold/hot days.

Coupled atmosphere-ocean general circulation models (GCMs) are used to make forecasts at multiple timescales, from medium-range weather forecasting, seasonal climate predictions, and long-term climate projections. The reason that GCMs can be used as operational models at these timescales is due to the predictability from different sources, such as initial conditions from the atmosphere and inertial dynamics from soil moisture and sea surface temperature. While the GCMs have demonstrated advanced configurations and realistic representations of the climate systems, the use of GCMs' predictions is still restricted by their coarse resolution and inherent systematic biases. To overcome these limitations, the GCMs' predictions at seasonal timescales are usually downscaled and bias-corrected before being used in hydrological applications (e.g., Wood et al., 2002; Luo and Wood, 2008; Yuan et al., 2013; Tian et al., 2014). The Climate Forecast System version 2 (CFSv2) is a recently developed GCM by the National Centers for Environmental Prediction (NCEP) (Saha et al., 2014). The CFSv2 model has run retrospectively to produce forecasts (hereafter reforecasts or hindcasts) every 5 days from 1982 to 2009 . Despite the availability of those CFSv2 daily hindcasts, temporal downscaling of the seasonal predictions is still routinely done from monthly to daily without using the daily forecast information (e.g., Yuan et al., 2013), with the assumption that the accuracy of daily information is limited at the seasonal timescale. At the sub-seasonal timescale, the usefulness of these daily or sub-daily precipitation or temperature forecasts compared to the monthly disaggregated forecasts has not been assessed.
The CFSv2 has fully coupled atmospheric, oceanic, and land components of the climate systems and demonstrated better performance for seasonal climate predictions when compared to other seasonal forecast models (Yuan et al., 2011). Since sub-seasonal precipitation or temperature forecasts are influenced jointly by the conditions of atmosphere, land, and ocean, CFSv2 has great potential to make skillful precipitation or temperature forecasts at sub-seasonal timescales.

Besides GCMs, teleconnections between large-scale climate patterns and local weather events have also been used to develop sub-seasonal precipitation or temperature forecasts. Recent examples include sub-seasonal winter temperature forecasts in North America using Madden-Julian Oscillation (MJO) or El Niño-Southern Oscillation (ENSO) conditions (Yao et al., 2011; Rodney et al., 2013; Johnson et al., 2013). In addition, Jones et al. (2011) found that the deterministic forecast skill of the CFSv1 for extreme precipitation in the contiguous United States (CONUS) during winter is higher when the MJO is active. With the updated version of CFS, the CFSv2 hindcasts allow one to re-examine this issue by assessing the influence of MJO or ENSO on the probabilistic temperature and precipitation forecast skill over the CONUS.

This study will conduct a comprehensive evaluation of the precipitation and temperature hindcasts at sub-seasonal timescales. Specifically, the aims of this study are to (1) assess the CFSv2 predictions for precipitation and temperature indices at different locations and seasons within the first 30 days, (2) compare weekly and fortnightly forecasting skill of the CFSv2 at different lead times, and (3) evaluate the effects of MJO and ENSO on the CFSv2 sub-seasonal forecast skill. The assessment includes mean values of subseasonal predictions as well as related temperature and precipitation indices at different forecast leads and scales. The downscaled CFSv2 monthly forecasts are compared with the native CFSv2 daily sub-seasonal forecasts. Furthermore, the influence of MJO or ENSO conditions on the CFSv2 categorical temperature and precipitation forecast skill is also assessed.

\section{Data and methodology}

CFSv2 had the state-of-the-art data assimilation and forecast model components of the climate system and became operational at NCEP in March 2011 (Saha et al., 2014). There were three different types of hindcasts (or reforecasts): 6-hourly time series from 9-month runs, 45-day runs, and season runs (Table 1). Figure 1 gives an example of the three hindcast configurations. CFSv2 hindcast data had a T126 spatial resolution (roughly $100 \mathrm{~km}$ ) and included several near-surface variables at a 6-hourly temporal resolution. The 1 season and 45-day reforecasts were initialized every day so that relatively new initial conditions could be incorporated into a large ensemble size for making a potentially more skillful 
Table 1. Configurations of the CFSv2 hindcast. UTC stands for Coordinated Universal Time.

\begin{tabular}{llll}
\hline Configurations & 9 -month runs & 1 season & 45-day runs \\
\hline Initiated day & $\begin{array}{l}\text { Every 5 days beginning } \\
\text { from 1 Jan of each year }\end{array}$ & Every day & Every day \\
Initiated UTC time & $0,6,12,18$ & 0 & $0,6,12,18$ \\
Covered period & $1982-2010$ & $1999-2010$ & $1999-2010$ \\
\hline
\end{tabular}

forecast. Nevertheless, we chose to use the 9-month reforecast. This is because the 9-month reforecast covered a much longer period (1982-2009) than 1 season and 45-day reforecasts (1999-2010), which ensures a larger sample size for a more robust evaluation, especially for the evaluation of skill conditioned on MJO and/or ENSO.

The daily precipitation total was aggregated from the 6hourly precipitation data; the daily mean temperature was obtained by averaging daily maximum and minimum temperature, which were extracted from the 6-hourly maximum and minimum temperature. The ensemble members for each month were constructed in the same way as the monthly hindcasts from CFSv2. For each year, the daily hindcast had 28 members in November and 24 members in other months with initial conditions at 00:00, 06:00, 12:00, and 18:00 UTC (Coordinated Universal Time) every 5 days. For example, the 24 ensemble members for January were initialized from the four cycles for each of 12, 17, 22, and 27 December and 1 and 6 January.

The forecast validation dataset was obtained from the North American Land Data Assimilation System version 2 (NLDAS-2; Xia et al., 2012). The forcing dataset of the NLDAS-2 merged large observation-based and reanalysis data and was widely used to drive land surface models over the CONUS. It had $0.125^{\circ}$ (approximately $12 \mathrm{~km}$ ) spatial resolution and hourly temporal resolution. The NLDAS-2 hourly precipitation (temperature) data were aggregated (averaged) into daily data.

Besides using CFSv2 daily hindcasts at its native spatial resolution (hereafter CFSv2 daily), the CFSv2 monthly hindcasts were also downscaled using the Bayesian merging (BM) method for hydrological applications (Luo et al., 2007). By comparing those two forecasts, it will help us understand the usefulness of the CFSv2 daily precipitation or temperature forecasts for hydrological applications compared to the monthly disaggregated forecasts. The BM method both spatially and temporally downscaled the CFSv2 monthly hindcasts from its native spatial resolution into daily hindcasts at a $0.125^{\circ}$ spatial resolution for hydrological applications. The BM method updated an observational climatology based on the hindcast skill using Bayesian theory and generated 20 daily ensemble members for each month using a historical-analog criterion and random selection. For a more detailed description of the BM method, please see Luo et al. (2007) and Luo and Wood (2008).
Ensemble forecasts of precipitation and temperature indices at sub-seasonal timescale were calculated by using daily forecasts directly from the CFSv2 and the BM downscaled CFSv2 monthly forecasts. Table 2 shows the forecast lead time for different periods and methods. For daily forecasts directly from CFSv2, all precipitation and temperature indices were calculated at 7-, 14-, and 30-day forecast timescales in the first month. For daily forecasts from the BM downscaled CFSv2 monthly data, the precipitation and temperature indices were only calculated at 30-day forecast timescales in the first month, since these forecasts were temporally disaggregated from monthly forecasts. It would be useful to look at the performance of the CFSv2 daily forecast in comparison with the daily data disaggregated from the monthly forecast.

Table 3 shows the precipitation and temperature indices calculated in this study. Following Zhang et al. (2011), a wet (dry) day was defined as days with precipitation above (below) $1 \mathrm{~mm}$ during the $n$-day period. The wet (dry) spell was defined as the number of consecutive wet (dry) days. Taking a 14-day forecast for WetSpell as an example (as is shown in Table 2), the first forecast lead was the number of consecutive rainy days from day 1 to day 14 forecasts. As a way of defining heat (cold) waves (e.g., Spinoni et al., 2015), the threshold for a high-(low-)temperature day was defined when the temperature was above (below) the 90th (10th) percentile of the climatological distribution of temperature during the $n$-day period for different months.

To validate the forecasts, the observed precipitation and temperature indices were calculated using the NLDAS-2 daily precipitation and temperature data. The NLDAS-2 daily precipitation and temperature data were upscaled using bin averaging in order to match CFSv2 spatial resolution. The percentiles of defining high (low) temperature were obtained separately from distributions of forecasts and observations. All ensemble forecasts including raw and BM downscaled CFSv2 forecasts were verified against the NLDAS-2. Take CFSv2 raw forecasts for January as an example; there are 24 ensemble members for all 30-day, 14-day, and 7-day forecasts. The 24-member ensemble forecasts were considered as being initialized on the first day of the month regardless of which day the individual member of the forecasts was initialized (e.g., 1-30 January, 1-14 January, and 1-7 January). All ensemble forecasts were converted into categorical forecasts in terciles with all observations converted into dichotomous values of 1 or 0 . The terciles were defined separately based on the individual distributions of the observations and the forecasts $(x)$, with $x<1$ st $/ 3$ rd percentile for the lower tercile, $1 / 3 \mathrm{rd} \leq x \leq 2 \mathrm{nd} / 3 \mathrm{rd}$ percentile for the middle tercile, and $x>2 / 3$ rd percentile for the upper tercile.

The categorical forecasts were evaluated using the Heidke skill score (HSS), a common performance metric used by the Climate Prediction Center (CPC) (e.g., Johnson et al., 2013; Wilks, 2011). The HSS assesses the proportion of correctly forecasted categories. The categorical forecast was assigned 


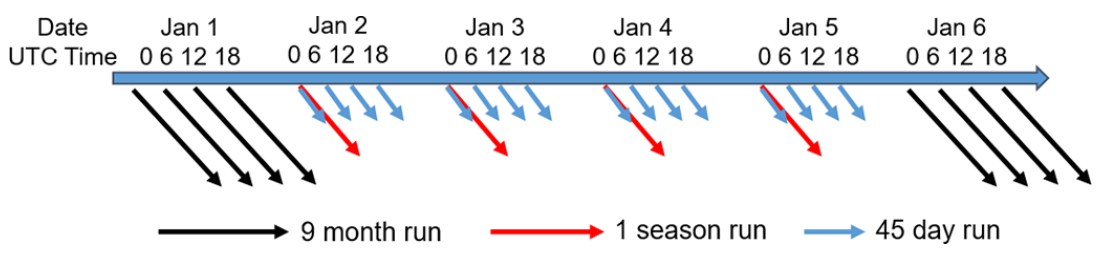

Figure 1. Three configurations of the CFSv2 hindcast: 9-month run, 1 season run, and 45-day run. UTC stands for Coordinated Universal Time.

Table 2. Forecast lead times for different periods and methods.

\begin{tabular}{|c|c|c|c|c|c|}
\hline \multirow[t]{2}{*}{ Period } & \multicolumn{4}{|c|}{ CFSv2 daily } & $\mathrm{BM}$ \\
\hline & Lead 1 & Lead 2 & Lead 3 & Lead 4 & Lead 1 \\
\hline 30-day & Day 1 to Day 30 & - & - & - & Day 1 to Day 30 \\
\hline 14-day & Day 1 to Day 14 & Day 15 to Day 28 & - & - & \\
\hline 7-day & Day 1 to Day 7 & Day 8 to Day 14 & Day 15 to Day 21 & Day 22 to Day 28 & - \\
\hline
\end{tabular}

to three forecast categories (upper, middle, or lower tercile) based on the highest of the three forecast probabilities. The tercile category probabilities were obtained by counting the ensemble members in each of the three categories and then by dividing by the ensemble size. The HSS is expressed as

$\mathrm{HSS}=\frac{(H-E)}{(T-E)} \times 100$.

The number of correctly forecasted categories is denoted as $H$. The random forecast, $E$, is the expected number of categories forecast correctly just by chance. In this study, since there are three forecast categories, $E$ is defined as one-third of the total number of forecasts, $T$. The HSS ranges from -50 (no correct forecasts) to 100 (perfect forecasts), with a value of 0 representing the same skill as randomly generated forecast or climatological forecast. The HSS above 0 indicates that the forecasts have skill. The HSS was calculated for each method (CFSv2 daily and BM), variable, index, grid point, month, and forecast time. Since the number of forecast-observation pairs was 28 for each point, the HSS estimation had considerable uncertainty given this relatively small sampling size. To quantify this uncertainty, a bootstrapping technique (Wilks, 2011; Hamilton et al., 2012) was applied to resample 28 samples (3000 times with replacement) from the 28-year reforecasts averaged over the CONUS. Then a number of 3000 HSS was calculated for constructing a distribution, with the confidence interval and significance level of the HSS estimated from this distribution. With this treatment of the HSS estimation uncertainty, we can determine that the HSS is significantly skillful when it is greater than a given significance level.

Since seasonal precipitation and temperature could be more predictable at larger scales (e.g., Luo and Wood, 2006; Roundy et al., 2015), it is worthwhile to also look at the sub-seasonal predictive skill over a larger spatial domain. Therefore, each forecast was averaged over each of the nine

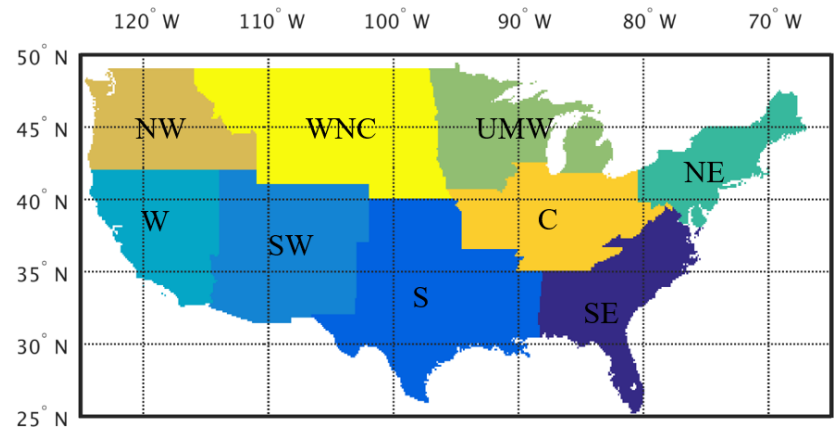

Figure 2. NCEI climate regions (described in Sect. 2) used as areal averaging domains for raw and BM downscaled CFSv2 forecasts. Regions are named as follows: Northwest (NW), West (W), Southwest (SW), West North Central (WNC), South (S), Upper Midwest (UMW), Central (C), Southeast (SE), and Northeast (NE).

National Centers for Environmental Information (NCEI, formerly known as National Climatic Data Center) climate regions as well as over the entire CONUS (Fig. 2). The HSS of the average forecasts over each of those regions was evaluated subsequently.

The skill assessment of $P_{\text {mean }}$ and $T_{\text {mean }}$ was conducted not only for all forecasts, but also for forecasts during active MJO or ENSO, or a combination of the two. MJO is the dominant mode of the sub-seasonal variability in the tropical atmosphere. The MJO index used in this study was from the Australian Bureau of Meteorology (http://www. bom.gov.au/climate/mjo/graphics/rmm.74toRealtime.txt) for the period of 1982 to 2009 . This index was defined by two leading principal components (PCs) from an empirical orthogonal function analysis of the combined nearequatorially averaged $850 \mathrm{hPa}$ zonal wind, $200 \mathrm{hPa}$ zonal wind, and satellite-observed outgoing longwave radiation data (Wheeler and Hendon, 2004). The pair of these two 
Table 3. Precipitation and temperature indices used in this study.

\begin{tabular}{lll}
\hline Index & Description & Period \\
\hline$P_{\text {mean }}$ & mean precipitation & 30-day, 14-day, and 7-day \\
RainWet & mean precipitation over wet days & 30-day, 14-day, and 7-day \\
RainDay & number of rainy days & 30-day, 14-day, and 7-day \\
WetSpell & maximum wet spell length & 30-day, 14-day, and 7-day \\
DrySpell & maximum dry spell length & 30-day, 14-day, and 7-day \\
\hline$T_{\text {mean }}$ & mean temperature & 30-day, 14-day, and 7-day \\
HighDay & number of high-temperature days & 30-day, 14-day, and 7-day \\
LowDay & number of low-temperature days & 30-day, 14-day, and 7-day \\
CosHighD & maximum number of consecutive high-temperature days & 30-day, 14-day, and 7-day \\
CosLowD & maximum number of consecutive low-temperature days & 30-day, 14-day, and 7-day \\
\hline
\end{tabular}

leading PC time series at a daily time step, called the Realtime Multivariate MJO series 1 (RMM1) and 2 (RMM2), defined eight MJO phases and an MJO amplitude. There were a few different ways to define active MJO events. The simplest criterion was to define MJO as RMM amplitude exceeded a certain threshold (e.g., Johnson et al., 2014), which did not consider minimum duration and eastward propagation of MJO. This study adopted a more rigorous definition of MJO: MJO days and events were identified using a pentad-averaged version of the Wheeler and Hendon RMM index subject to three major requirements as indicated by L'Heureux and Higgins (2008). A similar definition was also widely adopted by other researchers such as Jones (2009) and Jones and Carvalho (2011). In this work, ENSO was defined using the same criteria as CPC (http://www.cpc.ncep.noaa.gov/products/analysis_ monitoring/ensostuff/ensoyears.shtml). ENSO periods were based on a threshold of $\pm 0.5^{\circ} \mathrm{C}$ for the Oceanic Niño Index (3-month running means of sea surface temperature anomalies in the Niño 3.4 region). Warm or cold ENSO periods were identified when the threshold was met for a minimum of five consecutive overlapping seasons.

\section{Results}

\subsection{The 30-day forecast skill}

Figure 3 shows the average HSS for 30-day forecasts of precipitation indices calculated from the CFSv2 daily at different locations over December-January-February (DJF) and June-July-August (JJA). In DJF, the average skill of WetSpell over the CONUS was 34 (with a confidence interval $34 \pm 22$ ), which was much higher than the skill of the other indices; it showed high skill over most areas of the CONUS, including the Midwest and eastern parts. $P_{\text {mean }}$, RainDay, and DrySpell were skillful in the southeast and the southwest but also revealed skill in the other regions. RainWet showed minor skill over the entire region. The skill in JJA showed different spatial patterns with DJF. While $P_{\text {mean }}$ and Rain-

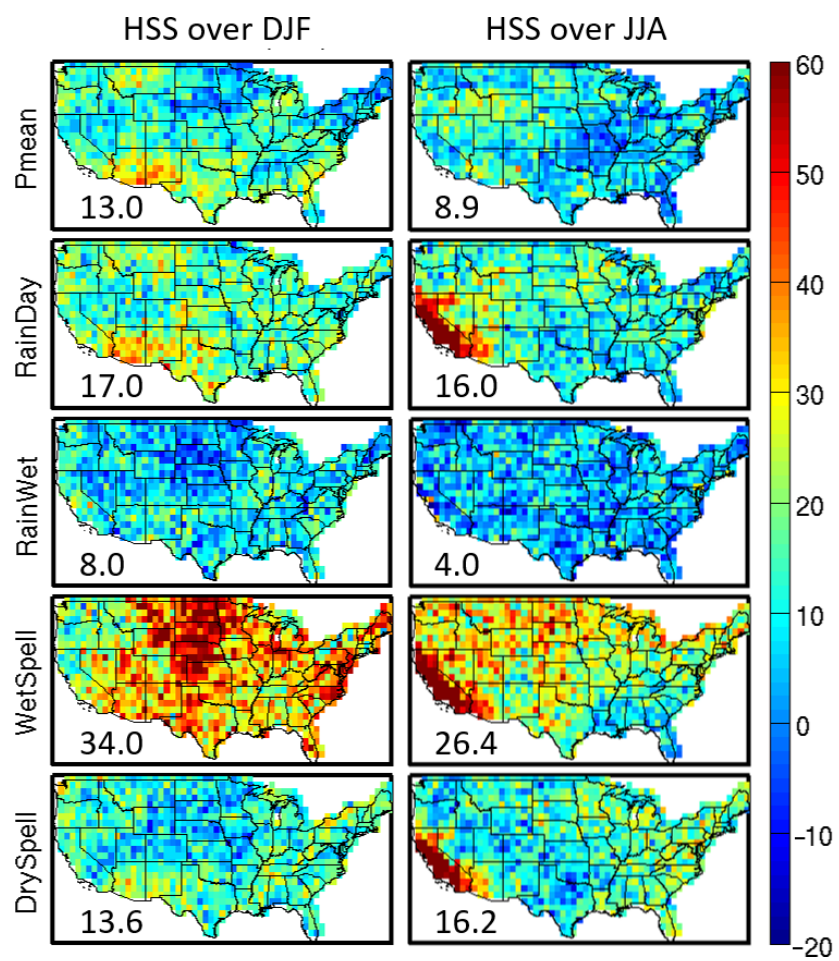

Figure 3. HSS of 30-day (from top to bottom columns) $P_{\text {mean }}$, WetRain, RainDay, WetSpell, and DrySpell from the CFSv2 daily hindcasts over DJF (left) and JJA (right). The number in the bottom left is the overall average.

Wet showed modest forecast skill in JJA over the CONUS, RainDay, WetSpell, and DrySpell all showed high skill in the western coastal regions, with the WetSpell showing some skill in the Midwest and northeast. The forecast skill for precipitation indices for MAM was between DJF and JJA, but the skill for SON was slightly lower than JJA (Fig. 4).

Spatial patterns in HSS were very different among the indices, particularly in July. We calculated the standard deviation (SD) for observed precipitation indices in July to further examine the interannual variability of those indices at each 

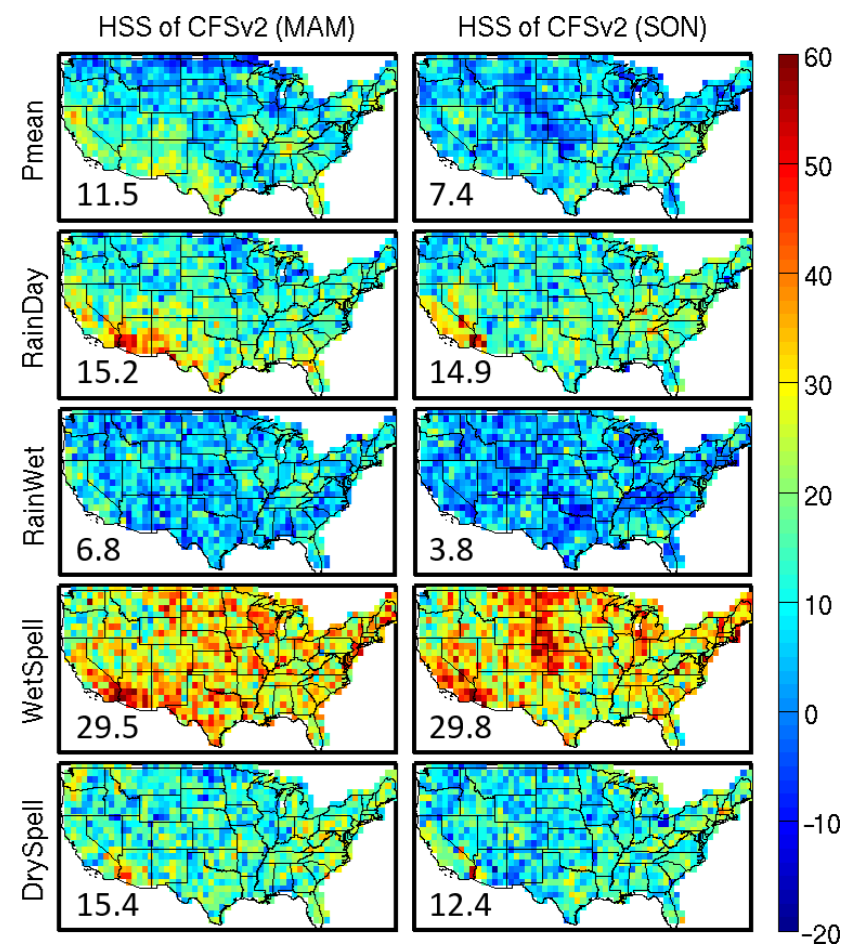

Figure 4. Same as in Fig. 3, but for MAM and SON.

grid point over the space. To compare relative temporal variability in space, the SD was normalized spatially to a range of 0 to 1 using a feature scaling method:

$\mathrm{SD}^{\prime}=\frac{\mathrm{SD}-\min (\mathrm{SD})}{\max (\mathrm{SD})-\min (\mathrm{SD})}$,

where SD is the standard deviation of the time series for each grid point, $\min (\mathrm{SD})$ and $\max (\mathrm{SD})$ are the minimum and maximum SD over all grid points, respectively, and $\mathrm{SD}^{\prime}$ is the normalized SD. Figure 5 shows the normalized standard deviation of 30-day precipitation indices in January and July over the 28-year period from 1982 to 2009 over the CONUS. By comparing interannual variability (Fig. 5) with the forecast skill over the space (Fig. 3), we found that regions showing lower interannual variability usually have higher skill than the regions with higher interannual variability. Particularly in JJA, for $P_{\text {mean }}$, the western CONUS showed relatively lower interannual variability and higher skill than the eastern CONUS; for RainDay, the western coastal areas showed much lower variability and higher skill than the other regions; for RainWet, all regions showed relatively equal variability and skills; for WetSpell, the southeastern CONUS showed higher interannual variability and lower skill than the other regions of the CONUS; for DrySpell, California and the eastern CONUS showed relatively lower interannual variability and higher skill than the other areas.

Figure 6 shows the average HSS for 30-day forecasts of temperature indices calculated from the CFSv2 daily at different locations over DJF and JJA. Overall, the temperature

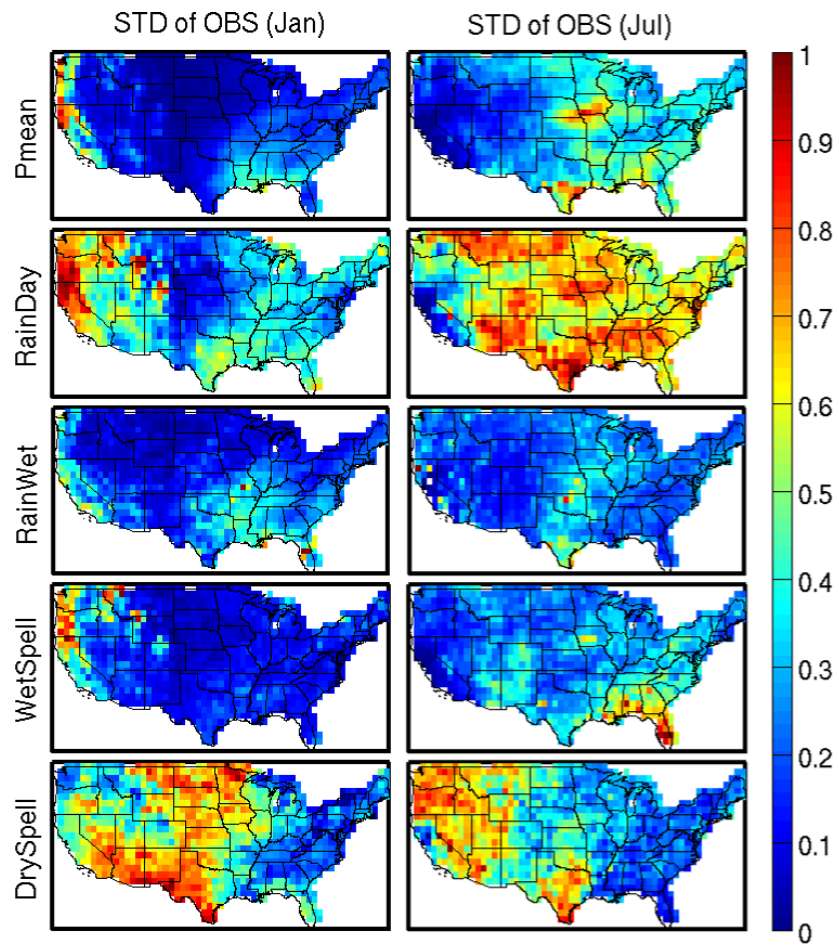

Figure 5. Spatially normalized standard deviations of observed 30day precipitation indices in January and July over the 28-year period from 1982 to 2009.

indices showed reasonably higher skill than the precipitation indices in both DJF and JJA. For DJF, $T_{\text {mean }}$ showed moderately high skill in the Great Lakes area and the eastern US; HighDay, LowDay, CosHighD, and CosLowD were skillful over most areas of the CONUS and the skill was particularly high for LowDay and CosLowD in the center or north of the Midwest region. The forecast skill of temperature indices in DJF showed different spatial patterns with JJA. $T_{\text {mean }}$ and LowDay showed high skill over the western inland area. CosLowD was skillful over a major area of the CONUS, particularly in the northeast. HighDay and CosHighD showed notable high skill around the south of the central area. The forecast skill for temperature indices was between DJF and JJA for MAM but slightly lower than JJA for SON (Fig. 7). It is worth noting that given the sample size $(N=28)$ used for calculating the HSS, the confidence interval of the HSS for each index is relatively wide. Based on the bootstrapping approach described earlier, the HSS was found to be significantly skillful (significantly above 0 at the 0.05 level) when it was greater than the number between 20 and 24, depending on the indices.

Figure 8 shows the average HSS for 30-day forecasts of precipitation and temperature indices calculated from the CFSv2 daily or the BM downscaled CFSv2 over 12 months for the CONUS and its consistent NCEI climate regions. The precipitation and temperature indices calculated from CFSv2 daily showed higher skill than BM for all regions. On aver- 


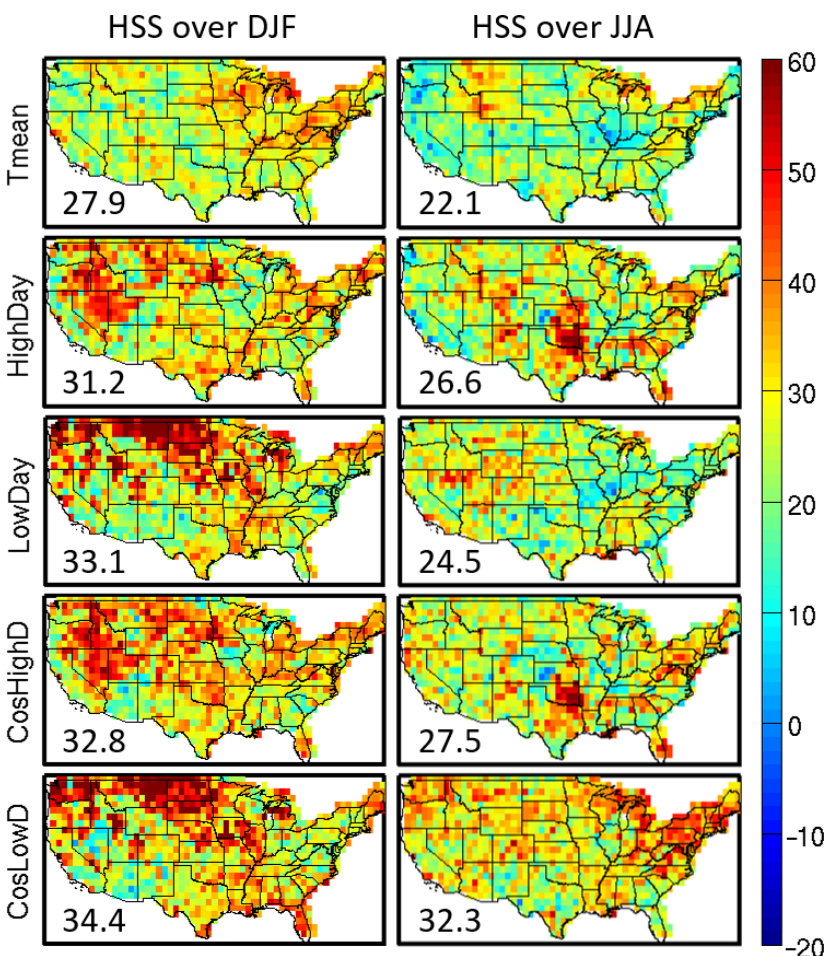

Figure 6. HSS of 30-day (from top to bottom columns) $T_{\text {mean }}$, HighDay, LowDay, CosHighD, and CosLowD from (from left to right rows) the CFSv2 daily hindcasts during DJF (left) and JJA (right). The number in the bottom left is the average.

age, the skill from the CFSv2 daily is approximately $20 \%$ higher than the skill from the BM, suggesting that the CFSv2 month-1 daily forecasts are potentially more useful than the temporally downscaled monthly forecasts for hydrological applications.

\subsection{Weekly and fortnight forecast skill at different lead times}

Figure 9 (Fig. 10) shows the average HSS of 14- and 7-day precipitation (temperature) indices forecasts from the CFSv2 daily over 12 months for the CONUS and its consistent NCEI climate regions. In general, the skill scores for precipitation indices were reasonably higher in the first 2 weeks than the second 2 weeks at both 14- and 7-day timescales since the first 2 weeks were within the range of weather forecast and were strongly influenced by the atmospheric initial conditions. While there were differences among regions, the skill scores for indices measuring frequency or duration of precipitation (i.e., RainDay, WetSpell, and DrySpell) or temperature extremes (i.e., HighDay, LowDay, CosHighD, and CosLowD) were equally skillful as those measuring mean precipitation or temperature during the first 2 weeks. Temperature indices showed notably higher skill than any precipitation index, particularly in weeks 3 and 4 . It was worth noting that the skill was higher for the 14-day forecast at the

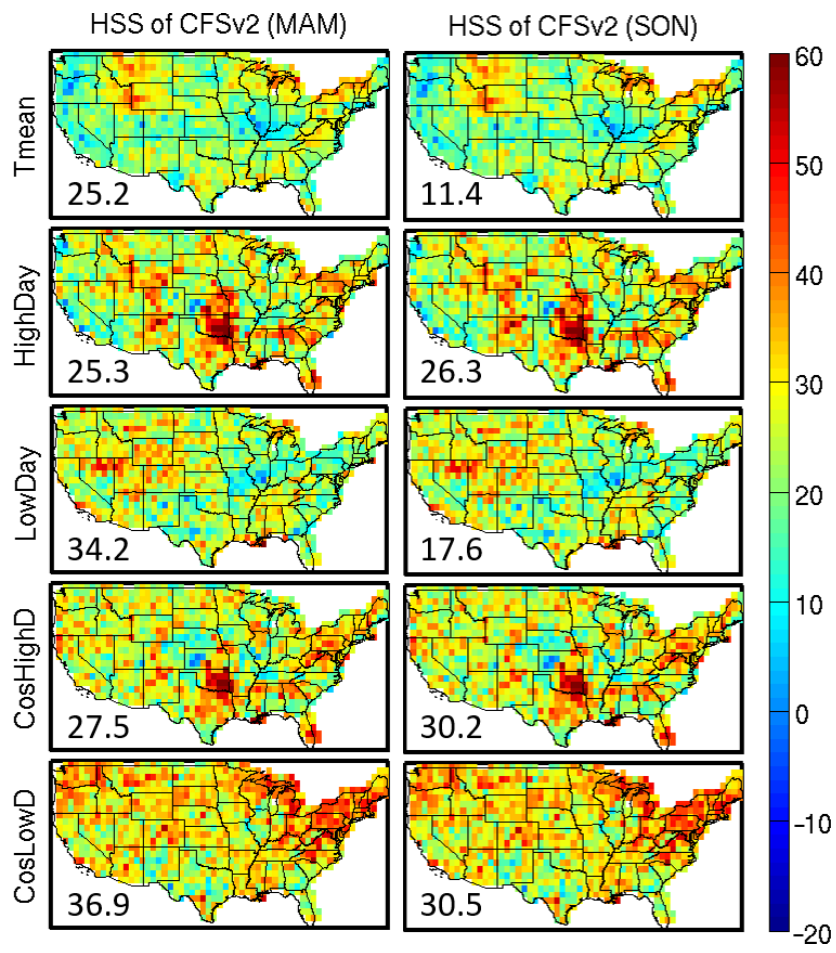

Figure 7. Same as in Fig. 6, but for MAM and SON.

first lead than for 7-day forecast in weeks 1 and 2 taken individually. The improved forecast skill indicated that the temporal noise in predictions can be reduced through averaging, as noted by Roundy et al. (2015).

\subsection{Effects of MJO and ENSO}

Figure 11 shows skill differences between $P_{\text {mean }}$ or $T_{\text {mean }}$ weeks 2-4 forecasts during active events (ENSO, MJO, or $\mathrm{MJO}+\mathrm{ENSO}$ ) and the forecasts during the whole period for the CONUS and its consistent NCEI climate regions. The $P_{\text {mean }}$ and $T_{\text {mean }}$ forecasts were calculated from the CFSv2 daily hindcasts. In general, weeks 3 and 4 forecasts performed better during anomalous ENSO or MJO states for $P_{\text {mean }}$ but not for $T_{\text {mean }}$.

For precipitation, the forecast skill was inconsistent for the anomalous ENSO, MJO, or combined ENSO and MJO phases relative to the whole period. There was a notable increase in skill when the forecasts were conditioned on active MJO for almost all regions, indicating the positive influence of MJO on the CFSv2 sub-seasonal precipitation forecasts. It is worthwhile noting that forecasts conditioned on combined MJO and ENSO, and forecasts conditioned on MJO, showed a similar level of positive skill with a few differences, which may due to the modulation effects of ENSO on MJO. For temperature, while the MJO, ENSO, or combined MJO and ENSO mostly showed positive effects on the skill for week 2 forecast, those influences became negative in most of the regions beyond week 2 . We further examined 

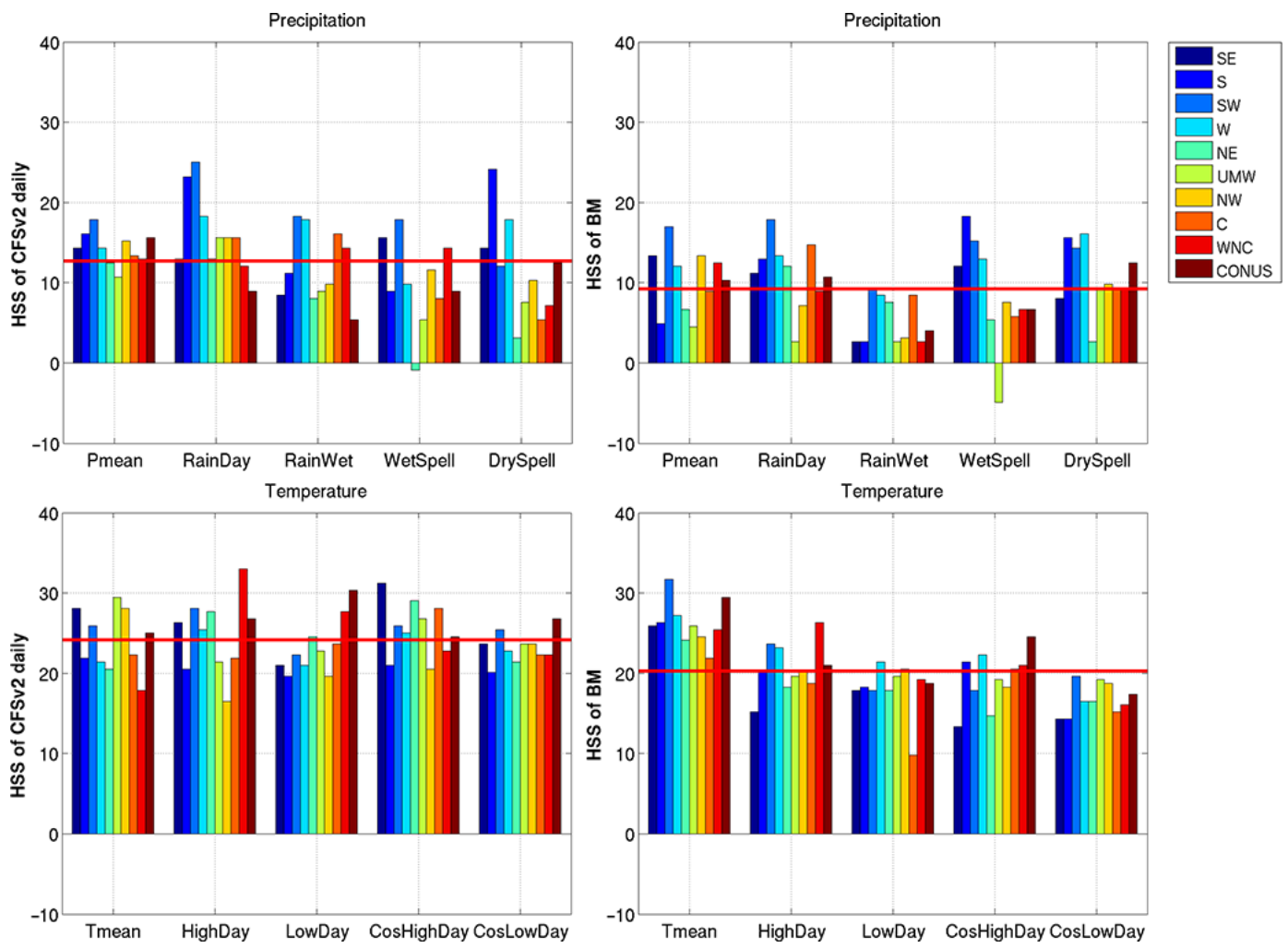

Figure 8. HSS of 30-day precipitation and temperature indices calculated from the CFSv2 and BM for the CONUS and its consistent NCEI climate regions. The red line is the average.
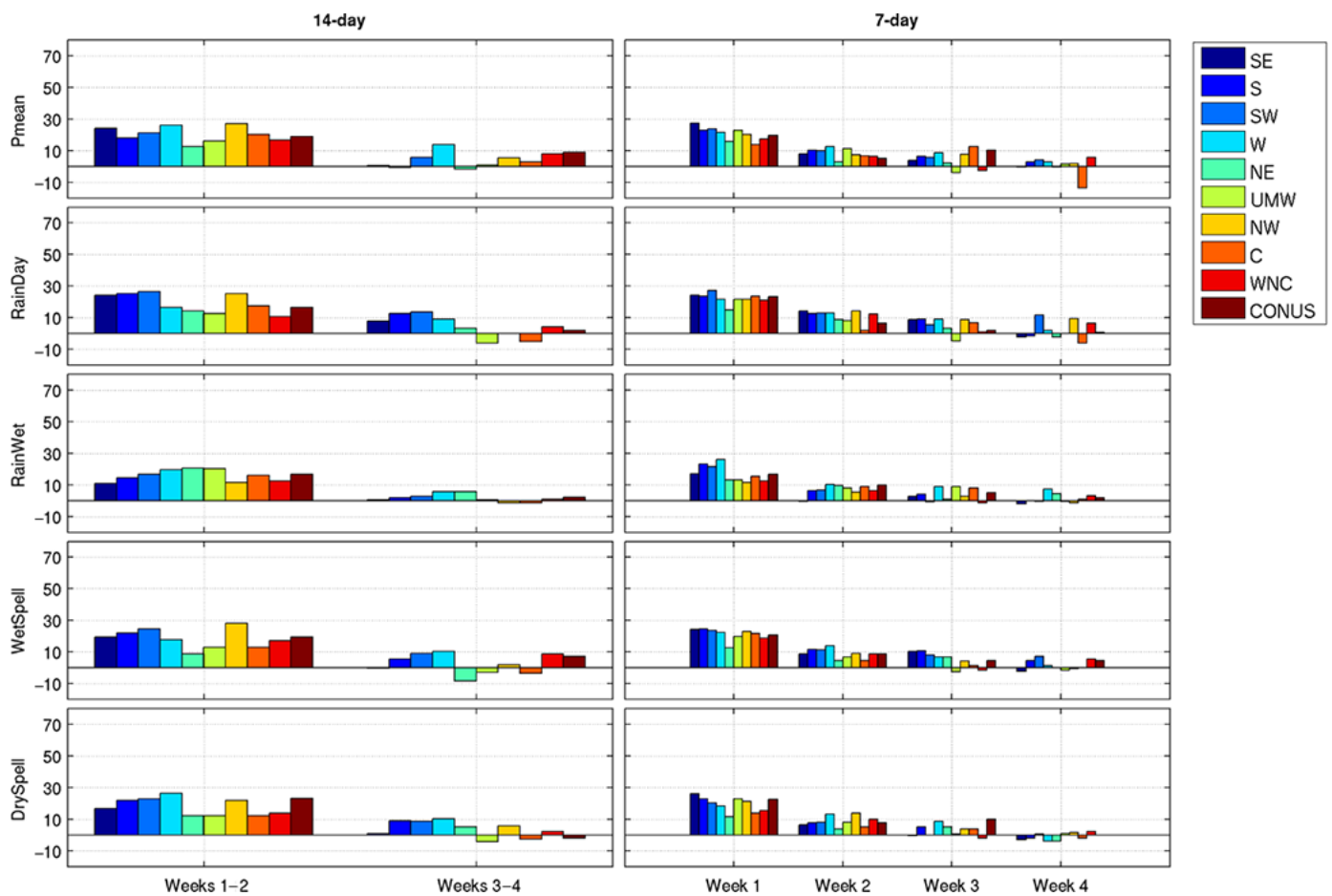

Figure 9. Mean HSS of 14- and 7-day (from top to bottom rows) $P_{\text {mean }}$, WetRain, RainDay, WetSpell, and DrySpell from the CFSv2 daily hindcasts for the CONUS and its consistent NCEI climate regions. 


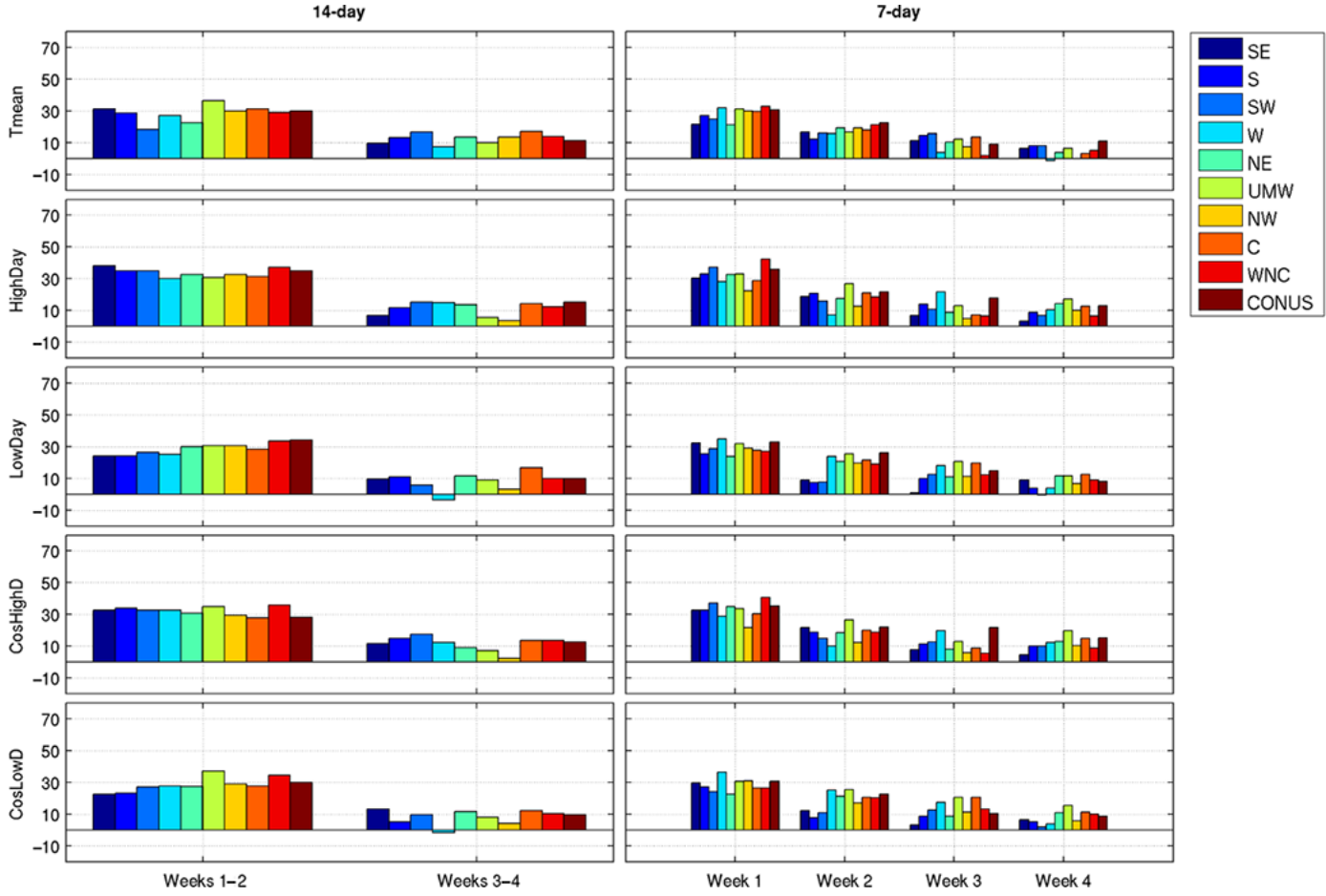

Figure 10. Mean HSS of 14- and 7-day (from top to bottom rows) $T_{\text {mean }}$, HighDay, LowDay, CosHighD, and CosLowD from the CFSv2 daily hindcasts for the CONUS and its consistent NCEI climate regions.

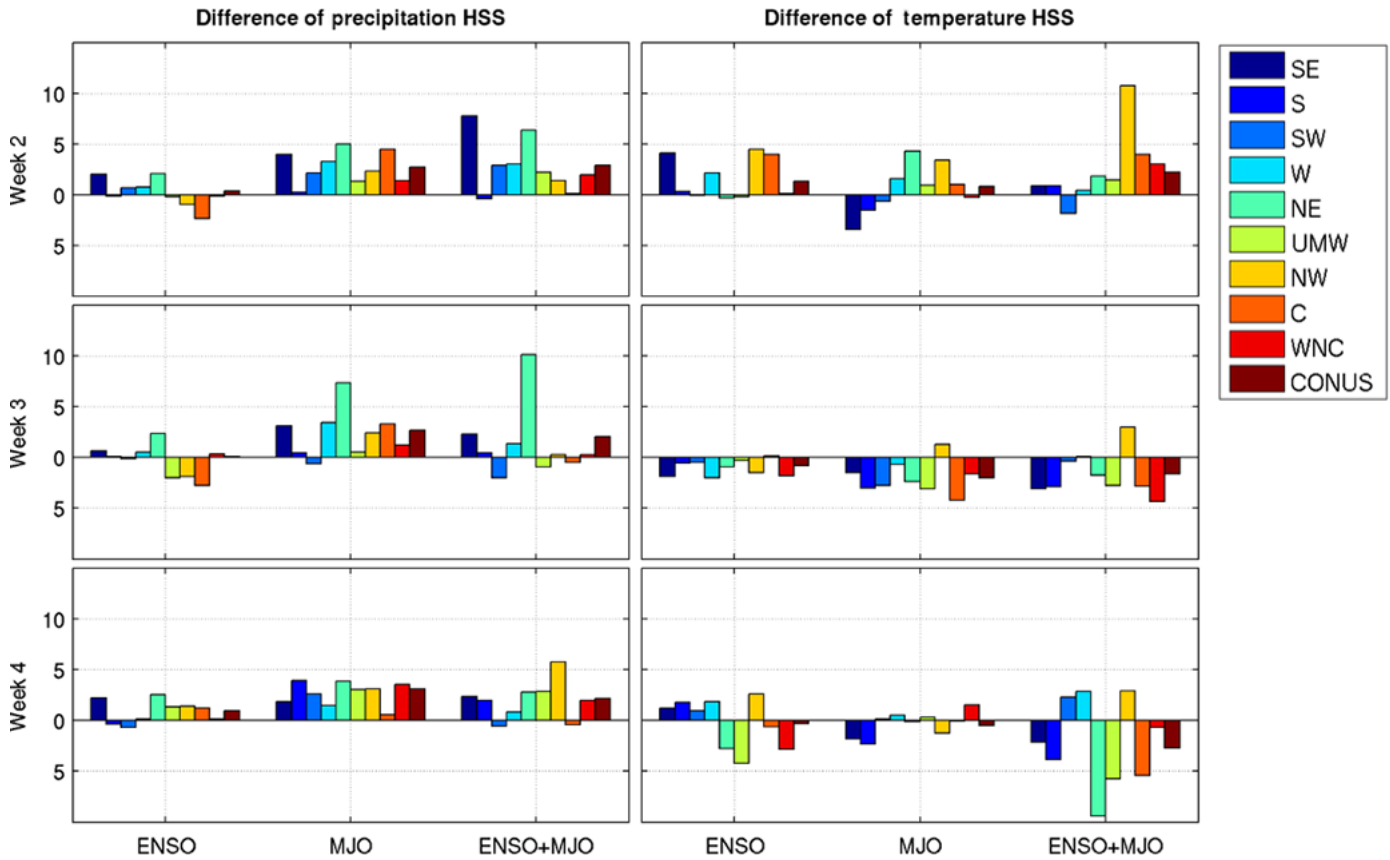

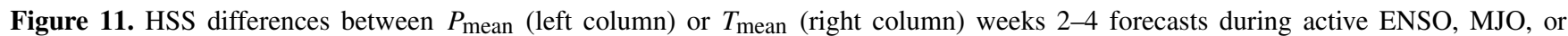
combined active ENSO and MJO (MJO+ENSO) phases and those during the whole period for the CONUS and its consistent NCEI climate regions. Positive values indicate more skillful forecasts during active MJO, ENSO, or ENSO+MJO phases. 


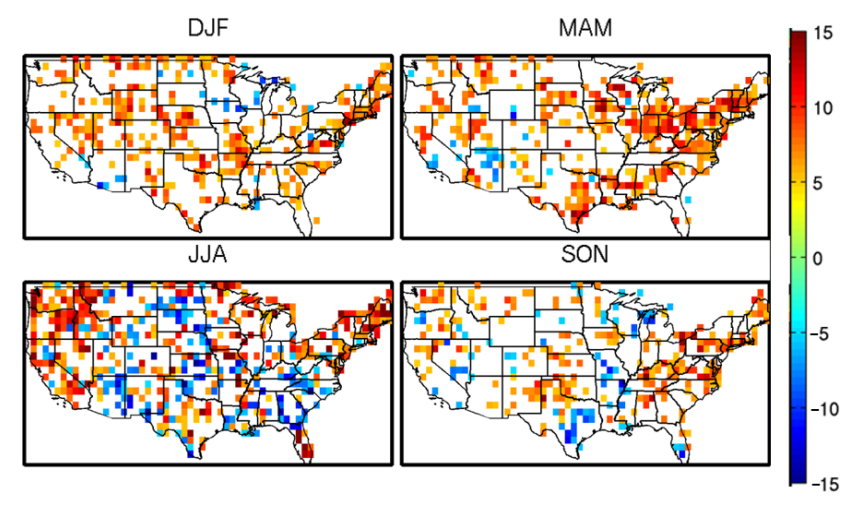

Figure 12. Differences between HSS of weeks $2-4 P_{\text {mean }}$ forecasts during active MJO phases and the whole period at different locations over the CONUS for DJF, MAM, JJA, and SON. The areas in white indicate the differences are not significant (at the 0.05 level).

differences between $P_{\text {mean }}$ or $T_{\text {mean }}$ average skill over weeks 2-4 for forecasts during the active MJO phase and the whole period at different locations and seasons (Figs. 12 and 13). We used a bootstrap technique for significance tests for the difference between the HSS during the active MJO phase and the whole period. We resampled 28 samples (3000 times with replacement) from the 28-year reforecast averaged over the CONUS. All 28 samples were used to calculate the HSS during the whole period. The subset of the 28 samples under active MJO events was used to calculate the conditional HSS. The difference between the HSS during the MJO and the whole period was then calculated. Since the resampling was conducted 3000 times, a number of 3000 HSS differences was obtained for constructing a distribution and used to estimate the confidence interval and significance level of the HSS. Similar to Peng et al. (2013), the significance level estimated based on the average over the CONUS was applied to test the local significance for each grid point over the region. The results are shown in Figs. 12 and 13.

In general, most skill was significantly different at different locations; MJO had strongly positive effects on CFSv2 sub-seasonal $P_{\text {mean }}$ forecast skill over the CONUS; the effects on $T_{\text {mean }}$ forecast skill were relatively weak and inconsistent among different regions. For precipitation, the influenced areas were greater during DJF and MAM than during JJA and SON, with the NE and NW regions being consistently influenced by MJO during four seasons. Aggregated over the CONUS, we further conducted statistical tests to compare whether precipitation forecast skills during active MJO, ENSO, or combined MJO and ENSO phases were greater than those during the whole period for DJF, MAM, JJA, and SON. We tested whether differences in mean HSS over the CONUS (averaged over 1024 grid points) were statistically significant at a $5 \%$ level. The Student's $t$ test showed that the forecast skill during active MJO or combined MJO and ENSO phases was significantly greater than

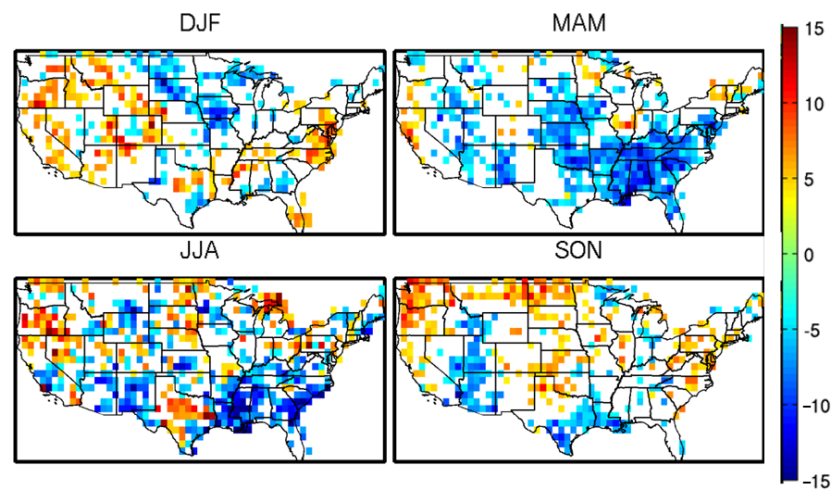

Figure 13. Same as in Fig. 12, but for $T_{\text {mean }}$.

those during the whole period ( $p<0.05$ ) for DJF, MAM, JJA, and SON; the forecast skill during active ENSO phases was significantly greater than those during the whole period for MAM. It is also worthwhile noting that the combined effects of MJO and ENSO were stronger than their individual effects, suggesting a potential benefit of using combined information of MJO and ENSO for sub-seasonal forecasts. Table 4 shows that there were much fewer ENSO events than MJO events during January 1982 to December 2009. The number of ENSO events could be limited enough to skew the skill score conditioned on ENSO.

\section{Discussion}

The CFSv2 sub-seasonal forecast skill was highly dependent on forecasting indices, regions, seasons, leads, and methods. The sub-seasonal forecasts for indices characterizing mean precipitation and temperature as well as frequency or duration of precipitation and temperature extremes showed skill in the first 2 weeks but no skill or modest skill for the second 2 weeks, since the first 2 weeks were within the range of medium-range weather forecasts. This finding is important given the sub-seasonal forecasting information is valuable to many decision makers. In particular, sub-seasonal forecasts for frequency or duration of precipitation and temperature extremes can be directly tailored to different application needs. For example, having the information of RainDay, WetSpell, and DrySpell weeks in advance will help farmers make decisions for irrigation scheduling to save water costs and improve crop yields. Short-term planning of urban water supply could also benefit from sub-seasonal forecasting information, since those indices describing frequency or duration of precipitation and temperature extremes are known to be directly related to the urban water demand forecasting (e.g., Donkor et al., 2012). As some temperature indices such as CosHighD and CosLowD were used to characterize heat/cold waves, forecasting information of these indices would also be useful for developing strategies for proactive disaster mitigation (e.g., frost damage to crops). 
Table 4. Active ENSO, MJO, and ENSO+MJO during January 1982 to December 2009. The red areas indicate active ENSO periods. The green areas indicate the periods with active MJO happening. The yellow areas indicate combined active ENSO and MJO events. The last three lines show the total number of ENSO, MJO, and ENSO+MJO events for each month.

\begin{tabular}{|c|c|c|c|c|c|c|c|c|c|c|c|c|}
\hline Year & Jan & Feb & Mar & Apr & May & Jun & Jul & Aug & Sep & Oct & Nov & Dec \\
\hline 1982 & & & & & & & & & & & & \\
\hline 1983 & & & & & & & & & & & & \\
\hline 1984 & & & & & & & & & & & & \\
\hline 1985 & & & & & & & & & & & & \\
\hline 1986 & & & & & & & & & & & & \\
\hline 1987 & & & & & & & & & & & & \\
\hline 1988 & & & & & & & & & & & & \\
\hline 1989 & & & & & & & & & & & & \\
\hline 1990 & & & & & & & & & & & & \\
\hline 1991 & & & & & & & & & & & & \\
\hline 1992 & & & & & & & & & & & & \\
\hline 1993 & & & & & & & & & & & & \\
\hline 1994 & & & & & & & & & & & & \\
\hline 1995 & & & & & & & & & & & & \\
\hline 1996 & & & & & & & & & & & & \\
\hline 1997 & & & & & & & & & & & & \\
\hline 1998 & & & & & & & & & & & & \\
\hline 1999 & & & & & & & & & & & & \\
\hline 2000 & & & & & & & & & & & & \\
\hline 2001 & & & & & & & & & & & & \\
\hline 2002 & & & & & & & & & & & & \\
\hline 2003 & & & & & & & & & & & & \\
\hline 2004 & & & & & & & & & & & & \\
\hline 2005 & & & & & & & & & & & & \\
\hline 2006 & & & & & & & & & & & & \\
\hline 2007 & & & & & & & & & & & & \\
\hline 2008 & & & & & & & & & & & & \\
\hline 2009 & & & & & & & & & & & & \\
\hline No. ENSO & 16 & 15 & 12 & 11 & 11 & 12 & 12 & 13 & 15 & 17 & 17 & 17 \\
\hline No. MJO & 22 & 22 & 24 & 23 & 24 & 15 & 15 & 15 & 16 & 24 & 23 & 25 \\
\hline No. ENSO+MJO & 12 & 12 & 10 & 7 & 8 & 4 & 6 & 6 & 9 & 13 & 13 & 14 \\
\hline & & & & & & & \\
\hline
\end{tabular}

The spatially and temporally downscaled CFSv2 monthly data using the BM method were compared with the CFSv2 daily data for sub-seasonal forecasts at its raw resolution. Since the 30-day precipitation and temperature indices calculated from CFSv2 daily hindcasts have higher skill than the $\mathrm{BM}$, the comparison of these two methods implies that daily forecasts from the CFSv2 are potentially more useful than those disaggregated from the monthly forecasts for application studies such as sub-seasonal hydrological forecasting.

This study demonstrated that the CFSv2 sub-seasonal forecast skill varies with space and time. These results identify seasons and regions where there is the potential for skillful sub-seasonal predictions for certain precipitation and temperature indices. For example, water managers in California trying to predict WetSpell and DrySpell have confidence to use the forecasts from CFSv2 during summer sea- sons, while a decision maker in the southeast may benefit little by using such information.

Sub-seasonal forecast skill can be further improved by understanding the sources of the skill. This study took a first look at the effects of MJO and ENSO on the CFSv2 subseasonal forecast skill. It was found that the presence of an active MJO improves weeks 2-4 categorical forecast of precipitation over most areas of the CONUS. This finding corresponds to the study of Jones et al. (2011), where improved deterministic CFSv1 forecast skill of extreme precipitation was also found during active MJO. We also compared the regions of improved skill based on MJO in this study (Fig. 9) with the results from Jones et al. (2011). While there were spatial differences, the regions of improved skill associated with MJO commonly occurred for the western coast of the CONUS. This result is consistent with current knowledge of the observed influence of the MJO on precipitation events along the CONUS western coast, which can be found at the NOAA CPC website (http://www.cpc.ncep.noaa.gov) under the MJO section. Forecast skill of precipitation and temperature is inherently associated with the capacity of CFSv2 in forecasting MJO. The CFSv2 has shown useful MJO prediction skill out to 3 weeks (Wang et al., 2014). Improvements of the representation of the MJO in CFSv2 will likely further extend the forecast skill of precipitation and temperature. Furthermore, recent studies have developed statistical forecasting models at sub-seasonal timescale using teleconnections of MJO and ENSO phases and local weather (e.g., Johnson et al., 2013). These statistical models could be potentially combined with CFSv2 forecasts to further improve the sub-seasonal forecast skill.

It is opportune to note some future directions of this work. Forecast skill could be potentially improved by having a larger ensemble size. A sensitivity study on ensemble size could be performed to assess whether a larger ensemble improves forecast skill. For future work, when 1 season or 45-day CFSv2 reforecasts (initialized everyday) are available over a longer period, we would choose to use those datasets instead of 9-month reforecasts (initialized every 5 days) in order to incorporate a large ensemble size for making a potentially more skillful forecast. Another approach to further improve the sub-seasonal forecast skill is through multi-model ensembles. The multi-model ensemble forecasts combine multiple seasonal forecast models and often have higher skill than individual models, since it has an increased ensemble size and a wider spectrum of possible forecasts that takes into account model uncertainty due to differences in model configuration and physics (e.g., Hagedorn et al., 2005). Here we highlight two important endeavors: the North American Multi-Model Ensemble (NMME2) system (Kirtman et al., 2013) is exploring sub-seasonal forecast in their next phase; the World Meteorological Organization (WMO) sub-seasonal to seasonal (S2S) prediction project (http://www.s2sprediction.net/) is archiving hindcast and real-time forecasts from a range of model systems. All 
of those efforts can facilitate sub-seasonal multi-model ensemble prediction and model inter-comparison studies. Furthermore, $\mathrm{CFSv} 2$ sub-seasonal precipitation and temperature forecasts can be used for subsequent application studies related to areas such as hydrology and agriculture. For example, flash drought refers to a sudden onset of high temperatures and decreases in soil moisture and is a disastrous event at sub-seasonal timescale (e.g., Mo and Lettenmaier, 2015; Wang et al., 2016). Sub-seasonal forecasting of flash drought will help decision makers develop mitigation strategies. The CFSv2 sub-seasonal precipitation and temperature forecasts can be used to drive land surface hydrological models to forecast soil moisture and evapotranspiration and consequently improve flash drought forecasts.

\section{Conclusions}

In this study, we have assessed the CFSv2 categorical subseasonal forecasts of precipitation and temperature indices over the CONUS. The categorical sub-seasonal forecast skill is highly dependent on forecasting indices, regions, seasons, and methods. Indices characterizing mean precipitation and temperature as well as measuring frequency or duration of precipitation and temperature extremes for 7-, 14-, and 30day forecasts were skillful depending on seasons and regions. The forecasts for 7- and 14-day temperature indices even showed skill at weeks 3 and 4, and are generally more skillful than precipitation indices. The forecasts for 30-day temperature and precipitation indices calculated from the statistically downscaled forecasts mostly showed lower skill compared to those calculated directly from the CFSv2 daily forecasts, indicating the potential usefulness of the CFSv2 daily forecasts for hydrological applications relative to the temporally disaggregated CFSv2 monthly forecasts. The presence of an active MJO improves weeks 2-4 categorical forecast of precipitation over most areas of the CONUS in the CFSv2 system. The sub-seasonal forecast skill of precipitation and temperature could be further improved through combining with teleconnection-based statistical sub-seasonal forecasting models or a multi-model ensemble.

Data availability. The CFSv2 reforecast data (Saha et al., 2014) were downloaded from the NOAA National Operational Model Archive and Distribution System (NOMADS, https://nomads.ncdc. noaa.gov/data/cfsr-rfl-ts9/). The NLDAS-2 forcing data (Xia et al., 2012) were obtained from the Goddard Earth Sciences Data and Information Services Center (GES DISC) (https://hydro1.gesdisc. eosdis.nasa.gov/data/NLDAS/NLDAS_FORA0125_H.002/).

Competing interests. The authors declare that they have no conflict of interest.
Acknowledgements. This research was supported by the NOAA Climate Program through grant NA12OAR4310090 entitled "A US National Multi-Model Ensemble ISI Prediction System", which is gratefully acknowledged. The third author also acknowledges the National Natural Science Foundation of China (no. 91547103). The authors would like to thank Michelle L'Heureux of the NOAA Climate Prediction Center for sharing daily MJO event data. The authors acknowledge PICSciE/OIT at Princeton University for the supercomputing support.

Edited by: A. Wood

Reviewed by: three anonymous referees

\section{References}

Brunet, G., Shapiro, M., Hoskins, B., Moncrieff, M., Dole, R., Kiladis, G. N., Kirtman, B., Lorenc, A., Mills, B., Morss, R., Polavarapu, S., Rogers, D., Schaake, J., and Shukla, J.: Collaboration of the weather and climate communities to advance subseasonal-to-seasonal prediction, B. Am. Meteorol. Soc., 91, 1397-1406, 2010

Donkor, E. A., Mazzuchi, T. A., Soyer, R., and Alan Roberson, J.: Urban water demand forecasting: review of methods and models, J. Water Res. Pl.-ASCE, 140, 146-159, 2012.

Garcia-Morales, M. B. and Dubus, L.: Forecasting precipitation for hydroelectric power management: how to exploit GCM's seasonal ensemble forecasts, Int. J. Climatol., 27, 1691, doi:10.1002/joc.1608, 2007.

Hagedorn, R., Doblas-Reyes, F. J., and Palmer, T. N.: The rationale behind the success of multi-model ensembles in seasonal forecasting - I. Basic concept, Tellus A, 57, 219-233, 2005.

Hamilton, E., Eade, R., Graham, R. J., Scaife, A. A., Smith, D. M., Maidens, A. and MacLachlan, C.: Forecasting the number of extreme daily events on seasonal timescales, J. Geophys. Res.Atmos., 117, D03114, doi:10.1029/2011JD016541, 2012.

Hansen, J. W., Challinor, A., Ines, A. V. M., Wheeler, T., and Moron, V.: Translating climate forecasts into agricultural terms: advances and challenges, Clim. Res., 33, 27-41, 2006.

Hudson, D., Marshall, A., and Alves, O.: Intraseasonal forecasting of the 2009 summer and winter Australian heat waves using POAMA, Weather Forecast., 26, 257-279, 2011a.

Hudson, D., Alves, O., Hendon, H. H., and Marshall, A. G.: Bridging the gap between weather and seasonal forecasting: intraseasonal forecasting for Australia, Q. J. Roy. Meteor. Soc., 137, 673-689, 2011b.

Hudson, D., Marshall, A. G., Yin, Y., Alves, O., and Hendon, H. H.: Improving intraseasonal prediction with a new ensemble generation strategy. Mon. Weather Rev., 141, 4429-4449, 2013.

Johnson, N. C., Collins, D. C., Feldstein, S. B., L'Heureux, M. L., and Riddle, E. E.: Skillful Wintertime North American Temperature Forecasts out to 4 Weeks Based on the State of ENSO and the MJO, Weather Forecast., 29, 23-38, 2013.

Jones, C.: A Homogeneous Stochastic Model of the Madden-Julian Oscillation, J. Climate, 22, 3270-3288, 2009.

Jones, C. and Carvalho, L. M.: Stochastic Simulations of the Madden-Julian Oscillation Activity, Clim. Dynam., 36, 229246, 2011. 
Jones, C., Carvalho, L. M. V., Gottschalck, J., and Higgins, W.: The Madden-Julian Oscillation and the Relative Value of Deterministic Forecasts of Extreme Precipitation in the Contiguous United States, J. Climate, 24, 2421-2428, 2011.

Kirtman, B. P., Min, D., Infanti, J. M., Kinter, J. L., Paolino, D. A., Zhang, Q., van den Dool, H., Saha, S., Pena Mendez, M., Becker, E., Peng, P., Tripp, P., Huang, J., DeWitt, D. G., Tippett, M. K., Barnston, A. G., Li, S., Rosati, A., Schubert, S. D., Rienecker, M., Suarez, M., Li, Z. E., Marshak, J., Lim, Y.-K., Tribbia, J., Pegion, K., Merryfield, W. J., Denis, B., and Wood, E. F.: The North American Multimodel Ensemble: Phase-1 Seasonalto-Interannual Prediction; Phase-2 toward Developing Intraseasonal Prediction, B. Am. Meteorol. Soc., 95, 585-601, 2013.

L'Heureux, M. L. and Higgins, R. W.: Boreal Winter Links between the Madden-Julian Oscillation and the Arctic Oscillation, J. Climate, 21, 3040-3050, 2008.

Luo, L. and Wood, E. F.: Assessing the idealized predictability of precipitation and temperature in the NCEP Climate Forecast System, Geophys. Res. Lett., 33, L04708, doi:10.1029/2005GL025292, 2006.

Luo, L. and Wood, E. F.: Use of Bayesian Merging Techniques in a Multimodel Seasonal Hydrologic Ensemble Prediction System for the Eastern United States, J. Hydrometeorol., 9, 866-884, 2008.

Luo, L. and Zhang, Y.: Did we see the 2011 summer heat wave coming?, Geophys. Res. Lett., 39, L09708, doi:10.1029/2012GL051383, 2012.

Luo, L., Wood, E. F., and Pan, M.: Bayesian merging of multiple climate model forecasts for seasonal hydrological predictions, J. Geophys. Res.-Atmos., 112, D10102, doi:10.1029/2006JD007655, 2007.

Mo, K. C. and Lettenmaier, D. P.: Heat wave flash droughts in decline, Geophys. Res. Lett., 42, 2823-2829, 2015.

Orth, R. and Seneviratne, S. I.: Predictability of soil moisture and streamflow on subseasonal timescales: A case study, J. Geophys. Res.-Atmos., 118, 10963-10979, 2013.

Peng, P., Barnston, A. G., and Kumar, A.: A comparison of skill between two versions of the NCEP climate forecast system (CFS) and CPC's operational short-lead seasonal outlooks, Weather Forecast., 28, 445-462, 2013.

Robertson, A. W., Kumar, A., Peña, M., and Vitart, F.: Improving and Promoting Sub-seasonal to Seasonal Prediction, B. Am. Meteorol. Soc., 96, ES49-ES53, 2014.

Rodney, M., Lin, H., and Derome, J.: Subseasonal prediction of wintertime North American surface air temperature during strong MJO events, Mon. Weather Rev., 141, 2897-2909, 2013.

Roundy, J. K., Yuan, X., Schaake, J., and Wood, E. F.: A framework for diagnosing seasonal prediction through canonical event analysis, Mon. Weather Rev., 143, 2404-2418, 2015.

Saha, S., Moorthi, S., Wu, X., Wang, J., Nadiga, S., Tripp, P., Behringer, D., Hou, Y.-T., Chuang, H.-y., Iredell, M., Ek, M., Meng, J., Yang, R., Peña Mendez, M., van den Dool, H., Zhang, Q., Wang, W., Chen, M., and Becker, E.: The NCEP Climate Forecast System Version 2, J. Clim., 27, 2185-2208, 2014.

Sankarasubramanian, A., Lall, U., Devineni, N., and Espinueva, S.: The role of monthly updated climate forecasts in improving intraseasonal water allocation, J. Appl. Meteorol. Clim., 48, 1464 1482, 2009.
Spinoni, J., Lakatos, M., Szentimrey, T., Bihari, Z., Szalai, S., Vogt, J., and Antofie, T.: Heat and cold waves trends in the Carpathian Region from 1961 to 2010, Int. J. Climatol., 35, 4197-4209, 2015.

Tian, D., Martinez, C. J., and Graham, W. D.: Seasonal Prediction of Regional Reference Evapotranspiration Based on Climate Forecast System Version 2, J. Hydrometeorol., 15, 1166-1188, 2014.

Toth, Z., Peña, M., and Vintzileos, A.: Bridging the gap between weather and climate forecasting: research priorities for intraseasonal prediction, B. Am. Meteorol. Soc., 88, 1427-1429, 2007.

Troccoli, A.: Seasonal climate forecasting, Meteorol. Appl., 17, 251-268, doi:10.1002/met.184, 2010.

Vitart, F.: Monthly Forecasting at ECMWF, Mon. Weather Rev., 132, 2761-2779, 2004.

Vitart, F., Buizza, R., Alonso Balmaseda, M., Balsamo, G., Bidlot, J. R., Bonet, A., Fuentes, M., Hofstadler, A., Molteni, F., and Palmer, T. N.: The new VAREPS-monthly forecasting system: A first step towards seamless prediction, Q. J. Roy. Meteor. Soc., 134, 1789-1799, 2008.

Vitart, F., Robertson, A. W., and Anderson, D. L.: Subseasonal to Seasonal Prediction Project: bridging the gap between weather and climate, Bulletin of the World Meteorological Organization, 61, 23, 2012.

Wang, L., Yuan, X., Xie, Z., Wu, P., and Li, Y.: Increasing flash droughts over China during the recent global warming hiatus, Sci. Rep., 6, 30571, doi:10.1038/srep30571, 2016.

Wang, W., Hung, M.-P., Weaver, S., Kumar, A., and Fu, X.: MJO prediction in the NCEP Climate Forecast System version 2, Clim. Dynam., 42, 2509-2520, 2014.

Wheeler, M. C. and Hendon, H. H.: An All-Season Real-Time Multivariate MJO Index: Development of an Index for Monitoring and Prediction, Mon. Weather Rev., 132, 1917-1932, 2004.

White, C. J., Hudson, D., and Alves, O.: ENSO, the IOD and the intraseasonal prediction of heat extremes across Australia using POAMA-2, Clim. Dynam., 43, 1791-1810, 2014.

Wilks, D. S.: Statistical methods in the atmospheric sciences, Vol. 100, Academic press, 2011.

Wood, A. W., Maurer, E. P., Kumar, A., and Lettenmaier, D. P.: Long-range experimental hydrologic forecasting for the eastern United States, J. Geophys. Res.-Atmos., 107, ACL 6-1-ACL 6$15,2002$.

Xia, Y., Mitchell, K., Ek, M., Sheffield, J., Cosgrove, B., Wood, E., Luo, L., Alonge, C., Wei, H., Meng, J., Livneh, B., Lettenmaier, D., Koren, V., Duan, Q., Mo, K., Fan, Y., and Mocko, D.: Continental-scale water and energy flux analysis and validation for the North American Land Data Assimilation System project phase 2 (NLDAS-2): 1. Intercomparison and application of model products, J. Geophys. Res.-Atmos., 117, D03109, doi:10.1029/2011JD016048, 2012.

Yao, W., Lin, H., and Derome, J.: Submonthly forecasting of winter surface air temperature in North America based on organized tropical convection, Atmosphere-Ocean, 49, 51-60, 2011.

Yuan, X., Wood, E. F., Luo, L., and Pan, M.: A first look at Climate Forecast System version 2 (CFSv2) for hydrological seasonal prediction, Geophys. Res. Lett., 38, L13402, doi:10.1029/2011GL047792, 2011.

Yuan, X., Wood, E. F., Roundy, J. K., and Pan, M.: CFSv2-Based Seasonal Hydroclimatic Forecasts over the Conterminous United States, J. Clim., 26, 4828-4847, 2013. 
Yuan, X., Wood, E. F., and Liang, M.: Integrating weather and climate prediction: Toward seamless hydrologic forecasting, Geophys. Res. Lett., 41, 2014GL061076, doi:10.1002/2014GL061076, 2014.

Zhang, X., Alexander, L., Hegerl, G. C., Jones, P., Tank, A. K., Peterson, T. C., Trewin, B., and Zwiers, F. W.: Indices for monitoring changes in extremes based on daily temperature and precipitation data, Wiley Interdisciplinary Reviews: Climate Change, 2, 851-870, 2011
Zinyengere, N., Mhizha, T., Mashonjowa, E., Chipindu, B., Geerts, S., and Raes, D.: Using seasonal climate forecasts to improve maize production decision support in Zimbabwe, Agr. Forest Meteorol., 151, 1792-1799, 2011. 